Психология. Журнал Высшей школы экономики,

2021. T. 18. № 3. C. 451-467. DOI: 10.17323/1813-8918-2021-3-451-467

\title{
ПСИХОЛОГИЧЕСКИЕ ФАКТОРЫ ДОВЕРИЯ К ПОПУЛЯРНЫМ ВИДЕОБЛОГЕРАМ У СОВРЕМЕННОЙ МОЛОДЕЖИ
}

\author{
И.М. БОГДАНОВСКАЯ ${ }^{\text {, А.Б. УГЛОВА }}$, Н.Н. КОРОЛЕВА
}

\begin{abstract}
${ }^{a}$ Федеральное государственное бюджетное образовательное учреждение высшего образования «Российский государственный педагогический университет им. А.И. Гериена», 191186, Санкт-Петербург, набережная реки Мойки, 48
\end{abstract}

\section{Резюме}

Представлены результаты исследования психологических факторов доверия к популярным видеоблогерам у современной молодежи. Исследование доверия в видеоблогах представляет значительный интерес, так как, несмотря на значимость данной формы виртуального общения, количество отечественных теоретических и эмпирических исследований по данной проблеме невелико. В качестве методического инструментария исследования использованы авторская анкета, методика «Личностный дифференциал», методика «Вера в людей» М. Розенберга, рефлексивный опросник уровня доверия к себе, модифицированная методика межличностного доверия Р. Левицки, М. Стивенсон, Б. Банкер, методика оценки доверия к информации в электронных СМИ. В исследовании приняли участие 70 студентов российских вузов. В статье обсуждаются результаты описательного, корреляционного и факторного анализа. Установлено, что большая часть респондентов склонны доверять мнению видеоблогеров. Среди компонентов доверия наиболее ярко выделяется стремление к установлению тождества, идентичности с предпочитаемым видеоблогером. Новым результатом стало выявление взаимосвязи самооценки интереса и компетентности по отношению к тематике, обсуждаемой в видеоблогах, с общим уровнем доверия к видеоблогеру. Показано, что факторная структура доверия включает один независимый и два коррелированных фактора. Независимый фактор охватывает параметры самооценочной компетентности в жизненных сферах, обсуждаемых в видеоблогах, самооценку интереса, а также интегральную оценку доверия к себе. Взаимосвязанные факторы отражают преобладание когнитивных аспектов восприятия видеоблогера, рационального ожидания эквивалентного обмена и расчета полезностей либо аффективно окрашенного отношения к влогеру, основанного на общей вере в людей, стремлении к установлению с ним тождества, идентификации.

Ключевые слова: доверие, видеоблогеры, молодежь, Интернет, коммуникация, информация, интерес к тематике видеоблога, компетентность в тематике видеоблога.

\section{Введение}

В настоящее время интернет-технологии проникают практически во все сферы жизни современной молодежи: коммуникативную, познавательную,

Исследование выполнено в рамках государственного задания при финансовой поддержке Минпросвещения России (проект № FSZN-2020-0027). 
учебную, игровую. Интернет-пространство становится средой социализации представителей поколения «digital native», с раннего возраста погруженных в виртуальное взаимодействие, хотя они не всегда обладают цифровой грамотностью (Iglesias et al., 2021). Понятие «цифровое поколение», поколение next или поколение $\mathrm{Z}$ с позиции различных методологических подходов (философский, поколенческий, психологический и др.) не имеет четких возрастных границ и варьирует во временно́м диапазоне, нижняя граница которого 1985 г. (Шамис, Никонов, 2019). Существует множество разноплановых, не совпадающих мнений по поводу специфики «цифрового поколения», присущих ему психологических свойств и характеристик (Богачева, Сивак, 2019). Представляется, что идентифицирующим для современных молодых людей может выступать сам факт рождения в эпоху информационной революции и активного развития коммуникационных технологий, формирование идентичности, картины мира и ее пространственно-временных параметров на границе реального и виртуального миров (Богдановская и др., 2015). Взросление и формирование личности современной молодежи проходит в контексте новых коммуникативных практик, культурных сдвигов в общении, связанных с постоянной включенностью в сетевую коммуникацию. Интенсивное использование интернет-технологий порождает и транслирует смыслы, которые обосновывают и отчасти объясняют высокую популярность сообществ блогеров и видеоблогов в социальных сетях. Влияние лидеров мнений в социальных сетях на молодежь сегодня превосходит ресурсы традиционных медиа. Персонализированная, эмоционально окрашенная информация в блогах позволяет его читателям и автору развивать вре́менные социальные отношения, обмениваться новостями и мнениями, оказывать психологическое воздействие друг на друга (Chai, Kim, 2010; Colucci, Cho, 2014). По этим причинам блоги стали одной из наиболее популярных областей виртуального пространства и важной формой общения для современной молодежи.

\section{Личный блог как форма виртуального общения}

Блог может быть определен как лента сообщений различной тематики, которая периодически обновляется, комментируется и коллективно обсуждается (Демченков, Заднепрянская, 2015). С. Колуччи, С. Чой и др. (Chai, Kim, 2010; Colucci, Cho, 2014) определяют блог как хронологическую публикацию личных мыслей и ссылок, часто в текстовой форме, но также включающую различные аудио- и визуальные форматы (видеоблоги - влоги, текстовые блоги, фотоблоги, микроблоги, подкасты). Блоги могут классифицироваться по различным основаниям: авторство, доступность, тематическая направленность, техническая основа, доменное имя, вид контента, цель создания (Ахмаева, 2020). Коммуникативные характеристики блога синтезируют черты различных интернет-жанров, таких как персональная страница, форум и др., которые характеризуются рядом технологических факторов: синхронность/асинхронность, постоянство/непостоянство записей, размер буфера сообщений, возможность анонимных сообщений, личных сообщений, 
фильтрация и цитирование сообщений (Belk, 2016). С другой стороны, блог включает в себя признаки традиционных литературных и эпистолярных жанров: интимного дневника; исповеди, биографии, автобиографии, репортажа с места событий и пр. (Горошко, 2007; Попов, 2008; Liao et al., 2013; Cunningham, Craig, 2017; Shahina, Uzakbayeva, 2020). Отличительной чертой личных блогов как формы виртуального общения является высокая степень свободы автора в выборе тематики, содержания и формы обсуждения проблем, а опосредованность взаимодействия обеспечивает авторам и читателям блогов необходимое чувство безопасности. Благодаря таким коммуникативным качествам они постепенно вытесняют традиционные новостные и аналитические программы (Ахмаева, 2020).

Наряду с позитивными изменениями, которые блогосфера внесла в стиль и образ жизни современного человека, социальные практики и особенности взаимодействия людей, она связана и с негативными аспектами сетевого общения, а также с новыми возможностями для манипулирования индивидуальным сознанием. «Темная» сторона серьезного или профессионального ведения блога связана с большими временнь́ми затратами, необходимостью поиска уникального контента, риском «застревания» в узкоспециализированной тематике. Профессиональное ведение блога может не давать гарантированного или ожидаемого дохода, могут возникнуть сложности с привлечением аудитории, отсутствием читателей либо повышенным вниманием к блогу негативно настроенных комментаторов. Последние обычно размещают под псевдонимом критические или оскорбительные комментарии, касающиеся внешнего вида, личности, жизненного выбора блогеров или коммерческого сотрудничества. Отмечаются нарушения и в содержании самих блогов, связанные с размещением недостоверного либо противоправного контента. Активно используются блоги в пропагандистской и контрпропагандистской борьбе, повторяя приемы воздействия традиционных СМИ, к которым добавляются новые возможности виртуальной коммуникации, одним из которых является видеоблог.

\section{Особенности коммуникации в видеоблоге}

Не существует единой и общепринятой классификации видеоблогов. С.А. Демченков и А.С. Заднепрянская (Демченков, Заднепрянская, 2015) предлагают следующие основания для классификации:

1) используемая платформа, определяющая технические характеристики материалов, аудиторию и динамику распространения;

2) технические параметры видеозаписи;

3) особенности построения видеоряда;

4) особенности построения звукоряда;

5) субъектная организация;

6) функционально-тематическая специфика.

Классификация по функционально-тематической специфике предполагает две большие группы: развлекательные (пародии, влоги, «вредные» советы, 
фан-видео) и познавательные (инструктивные блоги, видеообзоры) видеоблоги. В.А. Лущиков и др. (Лущиков, Терских, 2018) добавляют в эту классификацию «информационные видео» (например, политические блоги). Они же предлагают жанрово-тематическую классификацию видеоблогов: 1) видеообзор; 2) летсплей; 3) пранк; 4) обучающие видео; 5) влог; 6) интервью; 7) интернет-шоу; 8) реакция; 9) гайд; 10) вопрос-ответ; 11) скетч; 12) интернетсериал; 13) челлендж.

Видеоблоги имеют сходную структуру, включающую оформленную заставку видео, название, содержание видеоблога (видеоконтент), комментарии подписчиков. Отличительной особенностью данного формата является присутствие личности автора в видео или его закадровый голос, комментирующий происходящее на экране, что позволяет по сравнению с текстовыми блогами в большей степени проявиться личности автора.

К особенностям ведения видеоблога относятся сниженная степень анонимности коммуникации, повышение доверия к видеоблогеру со стороны аудитории и обострение чувства ответственности за свои слова и действия со стороны автора (Artomova, 2018). Дж. Аль-Менайес (Al-Menayes, 2015) отмечает, что в социальных сетях создаются виртуальные референтные группы, которые способны не только выступать заменой живому общению, но и выполнять функции фильтра, отбирающего из социальных норм и ценностей наиболее значимые для индивида. В этой ситуации ретрансляторами культурных норм становятся интернет-знаменитости и блогеры. В видеоблогах знаменитостей молодежь ищет модели поведения, образцы для подражания, старается уловить тренды - основные тенденции изменения моды, ценностей и стилей, которые определяют социальный статус. Видеоблогеры становятся не только медийными личностями, но и лидерами мнений, в связи с чем могут влиять на свою аудиторию: формировать предпочтения, способствовать изменению отношения к чему-либо. Понимая это, коммерческие компании начали налаживать контакты с видеоблогерами и взаимодействовать с ними с намерением использовать их интернет-ресурсы в собственных рекламных и маркетинговых целях (Shahina, Uzakbayeva, 2020). В то же время аудитория видеоблогеров не всегда точно понимает исходную мотивацию их сообщений, наличие (или отсутствие) заказчика, критерии достоверности информации. В связи с этим проблема доверия аудитории своему видеоблогеру приобретает особую актуальность.

\section{Психологические факторы доверия в видеоблогах}

C. Колуччи, С. Чой и др. (Chai, Kim, 2010; Colucci, Cho, 2014) систематизируют зарубежные психологические подходы к изучению доверия и выделяют следующие аспекты его понимания:

1) доверие как индивидуальная характеристика личности;

2) доверие как ожидание или убеждение, которое один человек имеет в отношении другого человека или людей;

3) доверие как рациональный экономический выбор, используемый субъектами, преследующими собственные интересы. 
В отечественных исследованиях доверие рассматривалось:

1) в контексте социально-психологических проблем (отношения со значимыми другими, дружеские и межгрупповые отношения, психологическое влияние, отношение к авторитетной персоне);

2) как ожидание, установка, отношение, состояние, чувство, личностное и групповое свойство;

3) как специфический субъектный феномен, сущность которого состоит в переживании актуальной значимости и априорной безопасности различных объектов;

4) как психологическое отношение, включающее интерес и уважение к объекту или партнеру, представление о потребностях, которые могут быть удовлетворены в результате взаимодействия с ним (Попов, 2008).

Зарубежные исследователи определяют онлайн-доверие как убеждение индивида в том, что партнер по коммуникации надежен, способен выполнять обещанные роли или обязательства, искренне заинтересован в благополучии своей аудитории и воздерживается от негативного поведения (Chapple, Cownie, 2017). Основываясь на этой концепции, доверие к видеоблогеру можно определить как ожидания аудитории от его личности, способности создавать интересный контент и желания делиться качественной информацией. В структуре доверия к видеоблогеру зарубежные исследователи выделяют такие характеристики, как уверенность в его компетентности, доброжелательности, высокую оценку репутации и личного опыта, убедительность и способность к взаимопониманию (Cho, 2006; Pasek, 2020). Одним из аспектов психологического исследования доверия в видеоблогах является анализ процессов идентификации, обеспечивающих постепенное сближение позиций влогера и его аудитории. Согласно самоотчетам зрителей каналов, со временем появляется чувство, что видеоблогер - это близкий друг или подруга. Этот эффект возникает благодаря контенту развлекательного характера, который подается «честно, без прикрас, как для своих» и позволяет зрителю лучше узнать личность видеоблогера (Солодовник, Басай, 2016). Существует и другой взгляд на проблему доверия к видеоблогеру, предполагающий, что оно может побуждаться посредством элементов дизайна блога, которые повышают качество восприятия информации (Zhang et al., 2009). Учитывая разнообразие подходов к проблеме доверия в видеоблогах и немногочисленность отечественных исследований данной проблемы, нами были сформулированы следующие исследовательские вопросы:

1) Существуют ли достоверно значимые различия в личностных характеристиках респондентов с высоким и низким уровнем доверия к популярным видеоблогерам?

2) В чем состоит специфика восприятия имиджа видеоблогера у респондентов с высоким и низким уровнем доверия?

3) Какие личностные характеристики взаимосвязаны с уровнем доверия к популярному видеоблогеру?

4) Какие переменные образуют психологическую структуру доверия к популярному видеоблогеру? 


\section{Методика исследования}

\section{Участники}

В исследовании приняли участие студенты российских вузов -70 человек в возрасте от 19 до 32 лет ( $\mathrm{M}=21.33, \mathrm{SD}=2.34)$, среди них 59 (84.3\%) женщин и 11 (15.7\%) мужчин. В ходе исследования респондентам предлагался список, включающий имена популярных видеоблогеров видеохостингового сайта YouTube, составленный на основе таких параметров, как число подписчиков и количество просмотров. Участникам исследования предлагалось выбрать предпочитаемого влогера, а если таковой отсутствовал, они могли указать свой вариант. Поскольку исследование проводилось онлайн, респонденты имели право найти выступление предпочитаемого видеоблогера, чтобы проводить оценку его имиджа в режиме непосредственного восприятия. Участие студентов в исследовании осуществлялось на добровольной основе; какоелибо вознаграждение не было предусмотрено.

\section{Методики}

Использовались авторская анкета, направленная на изучение интересов и самооценочной компетентности в тематике видеоблогов и доверия к видеоблогеру в указанных сферах (перечень сфер приведен в таблице 5), методики А.Б. Купрейченко (2008) «Вера в людей», рефлексивный опросник уровня доверия к себе, методика оценки доверия к информации в электронных СМИ, методика «Личностный дифференциал» Н.П. Фетискин (2002).

\section{Статистическая обработка}

Для статистической обработки эмпирических данных применялось лицензионное программное обеспечение, реализованное пакетом статистических программ Statistica 10.0. Были использованы следующие процедуры:

1) описательная статистика;

2) непараметрический U-критерий Манна-Уитни для выявления статистически достоверных различий по исследуемым показателям;

3) корреляционный анализ (коэффициент корреляции Спирмена);

4) факторный анализ был реализован методом главных компонент с «Varimax»-вращением факторов.

\section{Результаты исследования}

Для ответа на поставленные исследовательские вопросы респонденты были разделены по интегральной оценке доверия к видеоблогеру $(\mathrm{M}=68.48$, $\min =19, \max =133)$ на две группы:

1) высокий уровень доверия $-58.6 \%$;

2) низкий уровень доверия $-41.4 \%$. 
Согласно данным таблицы 1, участники выделенных групп сходным образом оценивают доверие к людям и доверие к самим себе, следовательно, личностные особенности доверия в группах с высоким и низким уровнем доверия к видеоблогеру не различаются.

Как видно из таблицы 2, наиболее значимыми аспектами межличностного доверия к видеоблогеру в 1-й группе являются те, которые основываются на стремлении к тождеству, идентификации с ним, в частности, приписывание влогеру сходных жизненных принципов, ценностей, ощущение близкого знакомства с ним.

Таблица 1

Сравнительный анализ установок на доверие к себе и другим людям

\begin{tabular}{|c|c|c|c|c|}
\hline Переменные & 1-я группа & 2-я группа & $\mathbf{U}$ & $\boldsymbol{p}$ \\
\hline Интегральная оценка доверия к людям & 1553.5 & 931.5 & 496.5 & 0.25 \\
\hline Интегральная оценка доверия к себе & 1532.0 & 953.0 & 518.0 & 0.36 \\
\hline
\end{tabular}

Примечание. Здесь и далее: 1-я группа - высокое доверие к видеоблогеру, 2-я группа - низкое доверие к видеоблогеру.

Таблица 2

Сравнительный анализ различных аспектов межличностного доверия к видеоблогерам

\begin{tabular}{|l|c|c|c|c|}
\hline \multicolumn{1}{|c|}{ Утверждение } & 1-я группа & 2-я группа & U & $\boldsymbol{p}$ \\
\hline $\begin{array}{l}\text { Я знаю, что он поступил бы так же, как я посту- } \\
\text { пил бы на его месте в различных неожиданных } \\
\text { ситуациях }\end{array}$ & 1597.5 & 887.5 & 422.5 & 0.036 \\
\hline $\begin{array}{l}\text { Пожалуй, я всегда смог бы предсказать его реак- } \\
\text { цию на то или иное событие }\end{array}$ & 1601 & 884 & 419 & 0.032 \\
\hline $\begin{array}{l}\text { Этот человек понимает, что оправдать доверие } \\
\text { своих подписчиков выгоднее, чем потерять его }\end{array}$ & 1602.5 & 882.5 & 417.5 & 0.031 \\
\hline $\begin{array}{l}\text { Мне кажется, я достаточно точно могу предска- } \\
\text { зать его поведение }\end{array}$ & 1613 & 872 & 407 & 0.022 \\
\hline $\begin{array}{l}\text { Мои и его мысли по поводу различных событий и } \\
\text { фактов совпадают }\end{array}$ & 1613 & 872 & 407 & 0.022 \\
\hline $\begin{array}{l}\text { Я наслышан от других людей о его хорошей репу- } \\
\text { тации }\end{array}$ & 1621.5 & 863.5 & 398.5 & 0.017 \\
\hline $\begin{array}{l}\text { Этот человек и я преследуем одни и те же цели в } \\
\text { жизни }\end{array}$ & 1621.5 & 863.5 & 398.5 & 0.017 \\
\hline Мне кажется, что я хорошо знаю его & 1634 & 851 & 386 & 0.011 \\
\hline У нас одни и те же жизненные ценности & 1645 & 840 & 375 & 0.008 \\
\hline $\begin{array}{l}\text { Мы с ним отстаиваем одни и те же жизненные } \\
\text { принципы }\end{array}$ & 1668.5 & 816.5 & 351.5 & 0.003 \\
\hline $\begin{array}{l}\text { Доверие к влогеру на основе тождества (интег- } \\
\text { ральная оценка) }\end{array}$ & 1619 & 866 & 3.78 & 0.009 \\
\hline
\end{tabular}


В таблице 3 показано, что различия в восприятии аудиторией имиджа видеоблогеров касаются всех параметров восприятия (сила, оценка, активность). Личностные особенности влогера, восприятие которых различается в обеих группах, относятся прежде всего к фактору «Сила» (напряженный, упрямый), фактору «Активность» (суетливый, раздражительный) и фактору «Оценка» (отзывчивый).

На основании восприятия видеоблогера доверяющими респондентами его можно описать как неуступчивого человека, характеризующегося наличием сдерживаемой силы, энергии, беспокойного, склонного экспрессивно реагировать, способного выражать в словах и поступках недовольство определенными людьми и событиями. Представляется, что эти особенности риторики выступают дополнительным способом воздействия на аудиторию, привлечения внимания и компенсации прямого контакта влогера со зрителями.

Согласно данным таблицы 4, различия в оценке качества информации, представленной в видеоблогах, касаются только такого ее аспекта, как полнота. Ориентируясь на ранговые суммы, можно отметить, что для первой группы наиболее значимым качеством информации является ее актуальность, тогда как во второй группе - это объективность и достоверность, хотя все качества информации более высоко оцениваются респондентами с высоким уровнем доверия видеоблогеру.

Таблица 3

Сравнительный анализ характеристик образа видеоблогера

\begin{tabular}{|l|c|c|c|c|}
\hline Шкалы личностного дифференциала & 1-я группа & 2-я группа & $\mathbf{U}$ & $\boldsymbol{p}$ \\
\hline Напряженный & 1805.00 & 680.00 & 245.00 & 0.000 \\
\hline Суетливый & 1696.00 & 789.00 & 354.00 & 0.004 \\
\hline Раздражительный & 1630.00 & 855.00 & 420.00 & 0.038 \\
\hline Упрямый & 1626.00 & 859.00 & 424.00 & 0.043 \\
\hline Отзывчивый & 1614.00 & 871.00 & 436.00 & 0.05 \\
\hline Оценка & 1599.00 & 886.00 & 451.00 & 0.048 \\
\hline Сила & 1615.00 & 870.00 & 435.00 & 0.045 \\
\hline Активность & 1605.00 & 880.00 & 445.00 & 0.05 \\
\hline
\end{tabular}

Сравнительный анализ качества информации в видеоблогах

\begin{tabular}{|l|c|c|c|c|}
\hline $\begin{array}{c}\text { Критерии оценки качества } \\
\text { информации }\end{array}$ & 1-я группа & 2-я группа & $\mathbf{U}$ & $\boldsymbol{p}$ \\
\hline Объективность & 1451.00 & 1034.00 & 590.00 & 0.96 \\
\hline Достоверность & 1481.50 & 1003.50 & 568.50 & 0.75 \\
\hline Полнота & 1614.50 & 870.50 & 435.50 & 0.05 \\
\hline Точность & 1526.50 & 958.50 & 523.50 & 0.39 \\
\hline Актуальность & 1601.00 & 884.00 & 449.00 & 0.07 \\
\hline
\end{tabular}


В таблице 5 приведены результаты ранжирования тематических сфер, которые чаще всего обсуждаются в видеоблогах по различным основаниям. Результаты самооценки изначально являлись количественными, поэтому была возможность определить достоверные различия между группами.

Таблица 5

Результаты ранжирования самооценки интереса, компетентности и доверия к видеоблогерам в различных тематических сферах (ранжирование по убыванию значимости)

\begin{tabular}{|c|c|c|c|c|c|c|c|c|}
\hline \multicolumn{3}{|c|}{$\begin{array}{c}\text { Самооценка интереса } \\
\text { к сферам }\end{array}$} & \multicolumn{3}{|c|}{$\begin{array}{l}\text { Самооценочная } \\
\text { компетентность }\end{array}$} & \multicolumn{3}{|c|}{$\begin{array}{c}\text { Доверие к влогеру } \\
\text { в сферах }\end{array}$} \\
\hline & \begin{tabular}{|c|}
$1-я$ \\
группа
\end{tabular} & \begin{tabular}{|c|}
$2-я$ \\
группа
\end{tabular} & & \begin{tabular}{c|}
$1-я$ \\
группа
\end{tabular} & $\left|\begin{array}{c}2-я \\
\text { группа }\end{array}\right|$ & & \begin{tabular}{|c|}
$1-я$ \\
группа
\end{tabular} & \begin{tabular}{|c|} 
2-я \\
группа
\end{tabular} \\
\hline & \begin{tabular}{|l|}
$\mathrm{R}$ \\
\end{tabular} & $\mathrm{R}$ & & $\mathrm{R}$ & $\mathrm{R}$ & & $\mathrm{R}$ & $\mathrm{R}$ \\
\hline $\begin{array}{l}\text { Психология, } \\
\text { отношения }\end{array}$ & 1 & 1 & $\begin{array}{l}\text { Психология, } \\
\text { отношения }\end{array}$ & 1 & 1 & Юмор & 1 & 1 \\
\hline Юмор & 2 & 6 & Музыка & 2 & 5 & Путешествия & 2 & 2 \\
\hline Путешествия & 3 & 7 & Юмор & 3 & 2 & Кино & 3 & 5 \\
\hline Искусство & 4 & 3 & Еда & 4 & 3 & Еда & 4 & 7 \\
\hline Музыка & 5 & 2 & $\begin{array}{l}\text { Мода и } \\
\text { красота }\end{array}$ & 5 & 11 & $\begin{array}{l}\text { Известные } \\
\text { личности }\end{array}$ & 5 & 9 \\
\hline Кино & 6 & 4 & Кино & 6 & 4 & Искусство & 6 & 11 \\
\hline $\begin{array}{l}\text { Мода и } \\
\text { красота }\end{array}$ & 7 & 11 & Искусство & 7 & 9 & Здоровье & 7 & 8 \\
\hline Образование & 8 & 8 & Образование & 8 & 10 & Образование & 8 & 10 \\
\hline Еда & 9 & 5 & Животные & 9 & 8 & Гаджеты & 9 & 16 \\
\hline Животные & 10 & 9 & Здоровье & 10 & 7 & Животные & 10 & 17 \\
\hline $\begin{array}{l}\text { Известные } \\
\text { личности }\end{array}$ & 11 & 12 & Путешествия & 11 & 6 & Музыка & 11 & 15 \\
\hline Здоровье & 12 & 10 & $\begin{array}{l}\text { Известные } \\
\text { личности }\end{array}$ & 12 & 13 & Видеоигры & 12 & 12 \\
\hline $\begin{array}{l}\text { Новости и } \\
\text { политика }\end{array}$ & 13 & 13 & $\begin{array}{l}\text { Новости и } \\
\text { политика }\end{array}$ & 13 & 14 & $\begin{array}{l}\text { Психология, } \\
\text { отношения }\end{array}$ & 13 & 3 \\
\hline Гаджеты & 14 & 17 & Видеоигры & 14 & 12 & Техника & 14 & 14 \\
\hline Видеоигры & 15 & 14 & Гаджеты & 15 & 16 & $\begin{array}{l}\text { Новости и } \\
\text { политика }\end{array}$ & 15 & 4 \\
\hline Техника & 16 & 16 & Спорт & 16 & 15 & $\begin{array}{l}\text { Мода и } \\
\text { красота }\end{array}$ & 16 & 13 \\
\hline Бизнес & 17 & 15 & Техника & 17 & 18 & Бизнес & 17 & 6 \\
\hline Спорт & 18 & 18 & Бизнес & 18 & 17 & Автомобили & 18 & 18 \\
\hline Автомобили & 19 & 19 & Автомобили & 19 & 19 & Спорт & 19 & 19 \\
\hline
\end{tabular}

Примечание. Выделены сферы по которым существуют достоверно значимые различия в указанных группах при $p<0.001$. 
Необходимо отметить, что 1-я группа достоверно выше оценивает свой интерес к таким сферам, как мода и красота, известные личности, гаджеты. Представители этой группы выше оценивают свою компетентность в сфере музыки, моды, искусства и образования. Степень доверия к мнению видеоблогера достоверно выше по каждой из указанных сфер, а наибольшие расхождения со 2-й группой отмечаются по темам «психология и отношения», «новости и политика».

Для определения психологической структуры доверия к видеоблогерам был проведен факторный анализ (метод главных компонент) с использованием коэффициентов ротации варимакс и факторных оценок. Мера адекватности выборки Кайзера-Мейера-Олкина $(\mathrm{KMO})=0.743$; в тесте сферичности Бартлетта $\chi^{2}=509.96, \mathrm{df}=66, \alpha=0.000$. Были извлечены три фактора с собственным значением больше единицы. Переменные с факторной нагрузкой показаны в таблице 6 .

Первый фактор (36\% общей дисперсии) был проинтерпретирован нами как «Рациональные аспекты доверия к видеоблогеру» на основании переменных, которые включились в его состав (базовые параметры восприятия, ожидание эквивалентного обмена и оценка полезности виртуальной коммуникации в видеоблоге, интегральная оценка доверия). Содержание второго фактора «Самооценка собственной компетентности» (16\% общей дисперсии)

Таблица 6

Факторные нагрузки и факторная структура психологических аспектов доверия к видеоблогерам

\begin{tabular}{|l|r|r|r|}
\hline \multicolumn{1}{|c|}{ Переменные } & \multicolumn{3}{c|}{ Компонент } \\
\cline { 2 - 4 } & 1 & 2 & \multicolumn{1}{c|}{3} \\
\hline Фактор «Сила» & $\mathbf{0 . 9 2}$ & 0.18 & -0.05 \\
\hline Фактор «Оценка» & $\mathbf{0 . 8 9}$ & 0.20 & 0.10 \\
\hline Фактор «Активность» & $\mathbf{0 . 8 8}$ & 0.22 & -0.11 \\
\hline $\begin{array}{l}\text { Доверие к влогеру, основанное на ожидании эквивалентного } \\
\text { обмена }\end{array}$ & $\mathbf{0 . 8 6}$ & 0.07 & 0.27 \\
\hline $\begin{array}{l}\text { Доверие к влогеру как результат рационального выбора и } \\
\text { расчета полезностей }\end{array}$ & $\mathbf{0 . 6 7}$ & -0.13 & 0.41 \\
\hline Интегральная оценка доверия к влогеру & $\mathbf{0 . 5 0}$ & 0.36 & 0.40 \\
\hline $\begin{array}{l}\text { Общая оценка собственной компетентности в сферах, } \\
\text { обсуждаемых в блогах }\end{array}$ & 0.00 & $\mathbf{0 . 9 0}$ & 0.06 \\
\hline Самооценка интереса к сферам, обсуждаемым в блогах & 0.09 & $\mathbf{0 . 8 5}$ & 0.20 \\
\hline Интегральная оценка доверия к себе & 0.17 & $\mathbf{0 . 4 2}$ & -0.14 \\
\hline Доверие к влогеру, основанное на тождестве, идентификациии & 0.58 & 0.03 & $\mathbf{0 . 6 8}$ \\
\hline Интегральная оценка доверия к людям & -0.09 & -0.01 & $\mathbf{0 . 8 4}$ \\
\hline Интегральная оценка качества контента в блогах & 0.30 & 0.26 & $\mathbf{0 . 3 2}$ \\
\hline Ехрl.Уаг & 4.37 & 1.97 & 1.77 \\
\hline Ргр.Тонl & 0.36 & 0.16 & 0.15 \\
\hline
\end{tabular}


включает переменные, отражающие оценку пользователями собственной способности ориентироваться в тематическом содержании влогов, связанную с общим доверием к себе. Третий фактор (15\% общей дисперсии) включает переменные, отражающие стремление читателей (зрителей) видеоблога к установлению тождества с его автором, которое связано с установкой на доверие к другим людям и оценкой качества контента в блоге. Это позволило обозначить данный фактор как «Доверие к видеоблогеру, основанное на стремлении к тождеству, идентификации». В таблице 7 отражены результаты проверки наличия взаимосвязей между выделившимися психологическими факторами доверия к видеоблогерам.

Как показано в таблице 7, факторная структура включает один независимый и два коррелированных фактора. Независимый фактор охватывает параметры самооценочной компетентности в жизненных сферах, обсуждаемых в блогах, и самооценку интереса к этим сферам, которые положительно связаны с интегральной оценкой доверия к себе. Взаимосвязанные факторы отражают преобладание когнитивных факторов восприятия влогера, рационального ожидания эквивалентного обмена и расчета полезностей либо аффективно окрашенного отношения к влогеру, основанного на общей вере в людей, стремлении к установлению с ними тождества, идентификации.

\section{Обсуждение результатов исследования}

Анализ результатов эмпирического исследования показывает, что современные молодые люди склонны в большей степени доверять видеоблогерам: так, группу с высоким уровнем доверия образовали $58.6 \%$ респондентов, а в группу с низким уровнем доверия вошли $41.4 \%$ участников исследования.

Результаты определения наиболее популярных видеоблогеров показали, что 48\% респондентов из группы с высоким уровнем доверия и 18\% из группы с низким уровнем доверия выбирают его из предложенного списка, сформированного на основе числа подписчиков и числа просмотров того или иного блога. Можно говорить о том, что эти участники исследования делают свой выбор на основе так называемого институализированного доверия, основанного на принятии мнения большинства. Самым популярным в обеих группах

Таблица 7

Взаимосвязь между психологическими факторами доверия к видеоблогерам

\begin{tabular}{|l|c|c|c|}
\hline \multicolumn{1}{|c|}{ Факторы } & F1 & F2 & F3 \\
\hline Фактор 1 «Рациональные аспекты доверия к видеоблогеру» & 1.00 & 0.31 & $\mathbf{0 . 4 9 * *}$ \\
\hline Фактор 2 «Самооценка собственной компетентности» & 0.31 & 1.00 & 0.10 \\
\hline $\begin{array}{l}\text { Фактор 3 «Доверие к видеоблогеру, основанное на стремле- } \\
\text { нии к тождеству, идентификации» }\end{array}$ & $0.49 * *$ & 0.10 & 1.00 \\
\hline
\end{tabular}

${ }^{* *} p<0.01$. 
оказался российский журналист и видеоблогер, ведущий авторского шоу на YouTube-канале «вДудь» (23\% vs. 11\%), канал которого в настоящий момент имеет 9.3 млн подписчиков и более 1.4 млрд просмотров. Формат данного авторского шоу отличается от других тем, что видеоблогер умеет объединять интересы самых разных людей вне зависимости от возраста, образования, уровня доходов, интересов. По выбору остальных видеоблогеров можно судить об интересах участников обеих групп. В группе с высоким уровнем доверия:

1) Руслан Усачев (10\%, 2.57 млн подписчиков), который рассказывает о событиях, произошедших в России и мире за последнее время, снимает фильмы и мультфильмы, а также видео о путешествиях по разным странам и городам;

2) Дмитрий Сыендук (8\%, 6.87 млн подписчиков) публикует видеоролики в жанрах треш, обзор, пародии, а также занимается переозвучкой мультфильмов;

3) Данила Поперечный (7\%, 3.27 млн подписиков) - стендап-комик.

В группе с низким уровнем доверия, кроме Ю. Дудя, общей популярностью пользуется один влогер - Дмитрий Куплинов (7\%, 10 млн подписчиков) - летсплейщик, обозреватель игр.

В ходе анализа личностных характеристик было выявлено, что установки на доверие к себе и другим людям, а также оценка качества информации в видеоблоге (кроме параметра «полнота») в группах с высоким и низким доверием являются сходными.

Все аспекты доверия к видеоблогеру, которое возникает в ходе виртуальной коммуникации, различаются в обеих группах, однако у всех респондентов в его структуре выделяется стремление к установлению тождества, идентичности с предпочитаемым видеоблогером. Для склонных доверять наиболее выраженным является утверждение «Мы с ним отстаиваем одни и те же жизненные принципы», связанное с общим уровнем доверия $\left(r_{\mathrm{s} 1}=0.35, p<0.05\right)$. В группе менее склонных к доверию - «Я знаю, что он поступил бы так же, как я поступил бы на его месте в различных неожиданных ситуациях» $\left(r_{\mathrm{s} 2}=0.43, p<0.01\right)$.

Все параметры восприятия имиджа видеоблогера связаны с общим уровнем доверия в обеих группах (фактор «Сила» $r_{\mathrm{s} 1}=0.48, \mathrm{p}<0.01$ vs. $r_{\mathrm{s} 2}=0.63$, $p<0.001$; фактор «Оценка» $r_{\mathrm{s} 1}=0.46, p<0.01$ vs. $r_{\mathrm{s} 2}=0.6, p<0.05$; фактор «Активность» $r_{\mathrm{s} 1}=0.45, p<0.01$ vs. $\left.r_{\mathrm{s} 2}=0.65, p<0.001\right)$, при этом доверяющие респонденты в большей степени акцентируют волевые качества, а менее доверяющие - характеристики эмоциональной сферы, экстравертированность. Взаимосвязи параметров восприятия выше в группе с низким уровнем доверия, возможно, это происходит по той причине, что этим респондентам важен имидж видеоблогера, в то время как доверяющие респонденты уже сформировали свое мнение и уделяют больше внимания качеству информационного контента.

Уровень интереса, самооценочной компетентности в тематической организации контента видеоблогов выше в группе доверяющих респондентов. В этой группе выявлены статистически значимые корреляция уровня интереса к определенным сферам с общим уровнем доверия к мнению видеоблогера: «Новости и политика» $\left(r_{\mathrm{s}}=0.59, p<0.001\right)$, «Еда» $\left(r_{\mathrm{s}}=0.34, p<0.05\right)$, «Юмор» $\left(r_{\mathrm{s}}=0.37, p<0.05\right)$, «Видеоигры» $\left(r_{\mathrm{s}}=0.41, p<0.01\right)$ и «Известные личности» 
$\left(r_{\mathrm{s}}=0.43, p<0.01\right)$; для самооценочной компетентности характерны такие взаимосвязи с общим уровнем доверия, как: «Автомобили» $\left(r_{\mathrm{s}}=0.36, p<0.05\right)$, «Еда» $\left(r_{\mathrm{s}}=0.34, p<0.05\right)$, «Техника» $\left(r_{\mathrm{s}}=0.34, p<0.05\right)$, «Известные личности» $\left(r_{\mathrm{s}}=0.36, p<0.05\right)$, Юмор» $\left(r_{\mathrm{s}}=0.37, p<0.05\right)$, «Видеоигры» $\left(r_{\mathrm{s}}=0.44\right.$, $p<0.05)$, «Новости и политика» $\left(r_{\mathrm{s}}=0.56, p<0.01\right)$. В группе с низким уровнем доверия для самооценки интереса к контенту это такие взаимосвязи, как: «Мода и красота» $\left(r_{\mathrm{s}}=0.38, p<0.05\right)$, «Видеоигры» $\left(r_{\mathrm{s}}=0.4 p<0.05\right)$, «Известные личности» $\left(r_{\mathrm{s}}=0.39, p<0.05\right)$, «Здоровье» $\left(r_{\mathrm{s}}=0.45, p<0.05\right)$ и $\ll$ Бизнес $\left(r_{\mathrm{s}}=0.63, p<0.001\right)$; для самооценочной компетентности таких взаимосвязей значительно меньше: «Мода и красота» $\left(r_{\mathrm{s}}=0.48, p<0.01\right)$ и «Бизнес» $\left(r_{\mathrm{s}}=0.56, p<0.01\right)$.

Полученные результаты согласуются с данными отечественных и зарубежных исследователей и позволяют описать психологическую структуру доверия к видеоблогеру: наибольшим значением обладают параметры восприятия его имиджа, рациональные аспекты доверия, основанные на представлениях о его репутации, популярности, полезности информации, которой он обменивается с аудиторией; вторым компонентом выступает такая личностная характеристика, как доверие к людям, что соотносится с идеей А.Б. Купрейченко о том, что данное свойство является одним из основных критериев доверия. Новым результатом стало выделение третьего компонента доверия к видеоблогеру, в качестве которого выступают самооценка интереса и самооценочная компетентность к тематике, обсуждаемой в видеоблогах.

Ограничения исследования связаны с небольшим объемом обследованной выборки, преобладанием в ее составе респондентов женского пола. Систематические исследования проблемы доверия в блогах можно продолжить в таких направлениях, как:

1) социально-демографические характеристики аудитории видеоблогеров и их связь с доверием к видеоблогеру;

2) личностные свойства и индивидуальных различия у представителей аудитории влогов;

3) личность видеоблогера, его коммуникативные качества, приемы речевого и внушающего воздействия;

4) жанровая и тематическая направленность информационного контента, сила его эмоционального воздействия, критерии качества информации;

5) влияние на доверие особенностей дизайна и навигации веб-сайта, на котором расположен влог, специфики управления влогом со стороны его владельца. Особой проблемой является исследование субъективных критериев оценки качества информационного контента, представленного в видеоблогах у современных молодых людей, их реакций на недобросовестные рекламные интеграции в видеоблогах, поведенческие проявления, связанные с доверием к видеоблогеру.

\section{Заключение}

В статье исследовались психологические факторы доверия к популярным видеоблогерам у современной молодежи. Несмотря на значимость видеоблогов 
в виртуальном общении, количество отечественных теоретических и эмпирических исследований данной проблемы невелико. Эмпирические данные, полученные в настоящем исследовании, могут рассматриваться как одно из оснований дальнейшего концептуального развития исследований доверия в видеоблогах. Методика исследования, объединяющая экспериментальный, опросный и психодиагностический методы, позволила сделать несколько важных выводов. Полученные результаты могут найти применение в работах психологов, социальных психологов, маркетологов, разработчиков дизайна сайтов. Интересным продолжением исследования может стать сравнение факторов, побуждающих доверие к видеоблогеру как в ситуации виртуального общения, так и в ходе продвижения торговых брендов или услуг.

\section{Литература}

Ахмаева, Л. Г. (2020). Приемы работы блогеров с мужской целевой аудиторией на примере российского блогера Дмитрия «Гоблина» Пучкова. Вестник университета, 8, 155-161. https://doi.org/10.26425/1816-4277-2020-8-155-161

Богачева, Н. В., Сивак, Е. В. (2019). Мифы о «поколении Z». М.: НИУ ВШЭ. https://ioe.hse.ru/pubs/share/direct/408113365.pdf

Богдановская, И. М., Иконникова, Г. Ю., Королева, Н. Н. (2015). Роль современной информационно-коммуникативной среды в формировании идентичности и образа мира современных подростков. Психологическая наука и образование, 7(1), 1-11.

Горошко, Е. И. (2007). Теоретический анализ Интернет-жанров. Жанры речи, 5, 370-389.

Демченков, С. А., Заднепрянская, А. С. (2015). Видео-блоги как разновидность новых медиа: проблемы типологии. В кн. Электронные средства массовой информачии: вчера, сегодня, завтра: материаль IX Всероссийской научно-практической конференции, 10 апреля 2015 2. (c. 58-60). СПб.: СПбГУП. https://www.gup.ru/events/news/smi/smi_2015.pdf

Купрейченко, А. Б. (2008). Психология доверия и недоверия. М.: Изд-во Институт психологии РАН. Лущиков, В. А., Терских, М. В. (2018). Жанрово-тематические и языковые особенности видеоблогов. Вестник Тамбовского университета. Серия: Общественные науки, 14, 57-75.

Попов, А. (2008). Блоги. Новая сфера влияния. М.: Манн, Иванов и Фербер.

Солодовник, Л. В., Басай, М. Ю. (2016). Виртуальные коммуникации как феномен межличностного общения в современном мире. Гуманитарий Юга России, 18(2), 257-263.

Фетискин, Н. П., Козлов, В. В., Мануйлов, Г. М. (2002). Социально-психологическая диагностика развития личности и малых групп. М.: Изд-во Института Психотерапии.

Шамис, Е., Никонов, Е. (2019). Теория поколений. Необыкновенный Икс. М.: Синергия.

Ссылки на зарубежные источники см. в разделе References после англоязычного блока.

Богдановская Ирина Марковна - доцент, кафедра психологии профессиональной деятельности, РГПУ им. А.И. Герцена, кандидат психологических наук.

Сфера научных интересов: киберпсихология, медиапсихология, психосемиотика, психосемантика. Контакты: ibogdanovs@herzen.spb.ru 
Королева Наталья Николаевна - профессор, кафедра психологии профессиональной деятельности, РГПУ им. А.И. Герцена, доктор психологических наук.

Сфера научных интересов: киберпсихология, психосемиотика, психосемантика, когнитивная психология.

Контакты: korolevanatalya@mail.ru

Углова Анна Борисовна - доцент, кафедра психологии профессиональной деятельности, РГПУ им. А.И. Герцена, кандидат психологических наук.

Сфера научных интересов: киберпсихология, психосемиотика, нарративная психология и психотерапия.

Контакты: anna.uglova@list.ru

\title{
Psychological Factors of Trust in Popular Video Bloggers among Modern Youth
}

\author{
I.M. Bogdanovskaya ${ }^{a}$, A.B. Uglova ${ }^{a}$, N.N. Koroleva ${ }^{a}$
}

${ }^{a}$ The Herzen State Pedagogical University of Russia, 48 Moika Emb., St. Pe-tersburg, Russian Federation, 191186

\begin{abstract}
The paper presents the results of the research on the psychological factors of trust in popular video bloggers among modern youth. The study of trust in video blogs is of considerable interest, since despite the importance of this form of virtual communication, the number of domestic theoretical and empirical studies on this problem is still small. The author's questionnaire, the method "Personal differential", the method "Faith in people" by M. Rosenberg, the reflexive questionnaire of the level of self-confidence, the modified method of interpersonal trust by R. Levitsky, M. Stevenson, B. Bunker, the method of assessing trust in information in electronic media were used as methodological tools of the study. The sample consisted of 70 students from Russian universities. The article discusses the results of descriptive, correlation and factor analysis. It was found that most of the respondents tend to trust the opinion of video bloggers. Among the components of trust, the striving to establish an identity with a preferred video blogger stands out most clearly. A new result was the identification of the relationship between the selfestimation of an interest and one's own competence in relation to the topics discussed in video blogs with a general level of trust in the video blogger. It is shown that the factor structure of trust includes one independent and two correlated factors. The independent factor covers the parameters of self-rated competence in life areas discussed in video blogs, self-estimation of an interest, as well as an integral assessment of self-confidence. The interrelated factors reflect the predominance of the cognitive aspects of the vlogger's perception, rational expectation of an equivalent exchange and calculation of utility, or an affectively colored attitude towards the vlogger based on a common belief in people, the desire to establish identity with him, and identification.
\end{abstract}

Keywords: trust, video bloggers, youth, Internet, communication, information, interest in the subject of a video blog, competence in the subject of a video blog. 


\section{References}

Akhmaeva, L. G. (2020). Techniques for bloggers working with a male target audience on the example of Russian blogger Dmitry "Goblin" Puchkov. Vestnik Universiteta, 8, 155-161. https://doi.org/10.26425/1816-4277-2020-8-155-161 (in Russian)

Al-Menayes, J. (2015). Motivations for using social media: An exploratory factor analysis. International Journal of Psychological Studies, 7(1), 43-50. https://doi.org/10.5539/ijps.v7n1p43

Artomova, Ye. A. (2018). Virtual language personality within internet discourse. In Trends in the development of modern linguistics in the age of globalization (pp. 44-47). Prague: Vedecko vydavatelske centrum Sociosfera-CZ s.r.o.

Belk, R. (2016). Extended self and the digital world. Current Opinion in Psychology, 10, 50-54. https://doi.org/10.1016/j.copsyc.2015.11.003

Bogacheva, N. V., \& Sivak, E. V. (2019). Mify o “pokolenii Z” [Myths of generation Z]. Moscow: HSE Publishing House. https://ioe.hse.ru/pubs/share/direct/408113365.pdf (in Russian)

Bogdanovskaya, I. M., Ikonnikova, G. U., \& Korolyova, N. N. (2015). The role of modern information and communication environment in shaping the identity and image of the world of modern teenagers. Psikhologo-Pedagogicheskie Issledovaniya [Psychological-Educational Studies], 7(1), 1-11. (in Russian)

Chai, S., \& Kim, M. (2010). What makes bloggers share knowledge? An investigation on the role of trust. International Journal of Information Management, 30(5), 408-415. https://doi.org/10.1016/j.ijinfomgt.2010.02.005

Chapple, C., \& Cownie, F. (2017). An investigation into viewers' trust in and response towards disclosed paid-for-endorsements by YouTube lifestyle vloggers. Journal of Promotional Communications, 5(2), 110-136.

Cho, J. (2006). The mechanism of trust and distrust forming and their relational outcomes. Journal of Retailing, 82(1), 25-35. https://doi.org/10.1016/j.jretai.2005.11.002

Colucci, C., \& Cho, E. (2014, December 30). Trust inducing factors of generation Y blog-users. International Journal of Design, 8(3), 113-122.

Cunningham, S., \& Craig, D. (2017). Being 'really real' on YouTube: authenticity, community and brand culture in social media entertainment. Media International Australia, 164(1), 71-81. https://doi.org/10.1177/1329878X17709098

Demchenkov, S. A., \& Zadnepryanskaya, A. S. (2015). Video-blogi kak raznovidnost' novyh media: problemy tipologii [Video blogs as a type of new media: problems of typology]. In Electronnye sredstva massovoi informatsii: vchera, segodnya, zavtra: Materialy IX Vserossiiskoi nauchno-prakticheskoi konferentsii, 10 aprelya $2015 \mathrm{~g}$. [Electronic media: yesterday, today, tomorrow: materials of the IX All-Russian Scientific and Practical Conference, April 10, 2015] (pp. 58-60). Saint Petersburg: SPbGUP. https://www.gup.ru/events/news/smi/smi_2015.pdf

Fetiskin, N. P., Kozlov, V. V., Manuilov, G. M. (2002). Sotsial'no-psikhologicheskaya diagnostika razzitiya lichnosti i malykh grupp [Socio-psychological diagnostics of the development of personality and small groups]. Moscow: Institute of Psychotherapy. (in Russian)

Goroshko, E. I. (2007). Teoreticheskii analiz Internet-zhanrov [Theoretical analysis of Internet genres]. Zhanry Rechi [Speech Genres], 5, 370-389. (in Russian)

Iglesias, A. I., Hernández-Martín, A., González, Y. M., \& Herráez-Corredera, P. (2021). Design, validation and implementation of a questionnaire to assess teenagers' digital competence in the area of 
communication in digital environments. MINECO, 13(12), Article 6733. https://doi.org/10.3390/su13126733

Kupreichenko, A. B. (2008). Psikhologiya doveriya i nedoveriya [The psychology of trust and distrust]. Moscow: Institute of Psychology of the RAS. (in Russian)

Liao, C., To, P., \& Liu, C. (2013). A motivational model of blog usage. Online Information Reviere, 37(4), 620-637. https://doi.org/10.1108/OIR-02-2012-0032

Lushchikov, V. A., \& Terskih, M. V. (2018). Zhanrovo-tematicheskie i yazykovye osobennosti videoblogov [Video blogging genre, thematical and linguistic properties]. Vestnik Tamborskogo Universiteta. Seriya: Obshchestvennye Nauki, 14, 57-75. (in Russian)

Pasek, A. (2020). Trust as an attribute of the internet good functioning. Science and World, 2(3(79)), $80-83$.

Popov, A. (2008). Blogi. Novaya sfera vliyaniya [Blogs. New sphere of influence]. Moscow: Mann, Ivanov i Farber.

Shahina, A. A., \& Uzakbayeva, A. A. (2020). Internet communication: general features. Academy, 5(56), $17-18$.

Shamis, E., \& Nikonov, E. (2019). Teoriya pokolenii. Neobyknovennyi iks [Generation theory. Unusual $\mathrm{X}]$. Moscow: Sinergiya.

Solodovnik, L. V., \& Basay, M. Y. (2016). Virtual communications as a phenomenon of interpersonal communication in the modern world]. Gumanitarii Yuga Rossii, 18(2), 257-263. (in Russian)

Zhang, X., Prybutok, V. R., Ryan, S., \& Pavur, R. (2009). A model of the relationship among consumer trust, web design and user attributes. Journal of Organizational and End User Computing, 21(2), 44-66. https://doi.org/10.4018/joeuc.2009040103

Irina M. Bogdanovskaya - Associate Professor, Department of Psychology of Professional Activity, the Herzen State Pedagogical University, PhD in Psychology.

Research Area: cyberpsychology, media psychology, psychosemiotics.

E-mail: ibogdanovs@herzen.spb.ru

Natalia N. Koroleva - Professor, Department of Psychology of Professional Activity, the Herzen State Pedagogical University, DSc in Psychology.

Research Area: cyberpsychology, psychosemiotics, cognitive psychology.

E-mail: korolevanatalya@mail.ru

Anna B. Uglova - Associate Professor, Department of Psychology of Professional Activity, the Herzen State Pedagogical University, PhD in Psychology.

Research Area: cyberpsychology, narrative psychology and psychotherapy.

E-mail: anna.uglova@list.ru 